\title{
The impact of cytochrome 450 and Paraoxonase polymorphisms on clopidogrel resistance and major adverse cardiac events in coronary heart disease patients after percutaneous coronary intervention
}

Zhaowei Zhang $^{1 *}$ (D), Mingxiao Chen ${ }^{1}$, Long Zhang ${ }^{2}$ and Qiang Zhao ${ }^{3}$

\begin{abstract}
Background: Clopidogrel is an inactive prodrug, it catalyzed into its active form by Cytochrome 450 and Paraoxonase-1(PON-1). polymorphisms of genes encoding these enzymes will affect the efficacy of Clopidogrel. The main objective of our study was to investigate the association of CYP2C19*2, CYP2C19*3 and PON-1Q192R polymorphisms with Clopidogrel resistance and major adverse cardiac events in Jin Hua district in the middle of Zhe Jiang Province in China.

Methods: One hundred sixty coronary heart disease patients with percutaneous coronary intervention, who were followed-up for 1 year, were enrolled in our study. These patients were co-administered aspirin $100 \mathrm{mg} / \mathrm{d}$ and clopidogrel $75 \mathrm{mg} / \mathrm{d}$ following a loading dose of $300 \mathrm{mg}$. The ADP-induced platelet aggregation rate was measured by Platelet aggregator. Genotypes of CYP2C19*2, CYP2C19*3, PON-1Q192R were determined using Sanger sequencing in all patients. Various clinical data were collected.

Results: The frequencies of CYP2C19*2, CYP2C19*3 and PON-1Q192R homozygous mutant genotypes were significantly lower in non-responders than those in responders. After for all variables, CYP2C19*2, CYP2C19*3 and PON-1Q192R independently increased the risk of clopidogrel resistance with adjusted ORs $46.65(95 \% \mathrm{Cl}, 1.77-25.04$; $p=0.005) ; 22.74(95 \% \mathrm{Cl}, 3.11-166.27 ; p=0.002) ; 5.69(95 \% \mathrm{Cl}, 1.06-30.47 ; p=0.042)$. Over a follow-up of 12 months, the incidence of major adverse cardiac events (MACE) in CYP2C19*1/*2, ${ }^{*} 1 /{ }^{*} 3,{ }^{*} 2{ }^{*} 2,{ }^{*} 2{ }^{*} 3$ was significantly higher than no mutant genotype (18/40vs.2/63,3/9vs.2/63, 11/6vs.2/63, 7/1vs2/63, respectively). There was no significant correlation between PON-1Q192R mutant allele and MACE.
\end{abstract}

Conclusion: Our study was first time to report on CYP2C19 and PON-1 polymorphisms in Jin Hua population in the middle of Zhe Jiang province in China. The carriage of CYP2C19*2 or *3 mutant allele significantly reduced the platelet response to clopidogrel and increase the MACE. The carriage of PON-1 mutant allele also significantly reduced the platelet response to clopidogrel, but would not increase the major adverse cardiac events after 1 year follow-up.

Trial registration: ChiCTR, ChiCTR1800018316. Registered 11 September 2018 - prospective registered, http://www. chictr.org.cn/edit.aspx?pid=30927\&htm=4.

Keywords: Cytochrome 450, Paraoxonase-1, Polymorphism, Clopidogrel resistance, Major adverse cardiac events

\footnotetext{
*Correspondence: quhaizhijia@163.com

'Department of Pharmacy, Jin Hua Municipal Central Hospital, Jin Hua 32100,

China

Full list of author information is available at the end of the article
}

(c) The Author(s). 2019 Open Access This article is distributed under the terms of the Creative Commons Attribution 4.0 International License (http://creativecommons.org/licenses/by/4.0/), which permits unrestricted use, distribution, and reproduction in any medium, provided you give appropriate credit to the original author(s) and the source, provide a link to the Creative Commons license, and indicate if changes were made. The Creative Commons Public Domain Dedication waiver (http://creativecommons.org/publicdomain/zero/1.0/) applies to the data made available in this article, unless otherwise stated. 


\section{Background}

Coronary Heart Disease (CHD) is a significant cause of morbidity and mortality in the world [1]. Percutaneous Coronary Intervention (PCI) is the principal revascularization strategy employed in the treatment of CHD [2]. Dual antiplatelet therapy (DAPT), with aspirin and Clopidogrel, is a basis for the care of patients after percutaneous coronary intervention (PCI) [3]. Despite adequate antiplatelet therapy, up to $10 \%$ of patients will still experience a recurrent acute ischemic event, this is probably because of significant interindividual variability in the clopidogrel response $[4,5]$.

Clopidogrel is an inactive prodrug. The absorption of Clopidogrel is mainly limited by P Glycol-.

protein (P-gp) which is encoded by ABCB1.Then it undergoes 2 sequential oxidative stages in order to be active. Firstly, clopidogrel catalyzed by Cytochrome 450 (CYP2C19, CYP2B6, CYP1A2) into 2-oxo-clopidogrel, then CYP3A4, CYP2C9 and the Paraoxonase (PON-1) enzyme transform 2-oxo-clopidogrel into its active form [6-8].It has been confirmed that CYP2C19 is the most important enzyme involved in clopidogrel response. Whereas genetic polymorphism of CYP2B6, CYP3A4, CYP2C9 showed minor effects on clopidogrel response [9]. Here, we mainly studied the association between PON-1Q192R, CYP2C19*2, CYP2C19*3 allelic variants and clopidogrel response. Several studies have been confirmed that carriers of the allelic variant (CYP2C19*2) is correlated with adverse cardiovascular events and low clopidogrel response [10,11]. whereas studies about the relevance between the allelic variant of CYP2C19*3, PON-1 Q192R and the clopidogrel response are discrepancy [12-15]. Moreover, the polymorphism of CYP2C19 and PON-1 varies considerably with both geographical location and ethnic group [16].In addition, To our knowledge, there are no studies about the relationship between genetic polymorphisms and clopidogrel resistance among the CHD patients in Jin Hua in the middle of Zhe Jiang province in China. The aim of our study was to determine the association between the allelic variant of CYP2C19*2, CYP2C19*3, PON-1 Q192R and clopidogrel resistance and major adverse cardiac events (MACE) among CHD patients in the middle of Zhe Jiang province in China.

\section{Methods}

\section{Study population}

This study was approved by the Ethics Committee of Zhe Jiang Provincial Jin Hua Municipal Central Hospital, China. 160 Chinese Han patients who were born in Jin Hua and diagnosed as CHD scheduling to undergo PCI were recruited into our study. We have calculated the sample size before the study by Quanto software. Power calculation was performed by Quanto software. Assuming a allele frequency of 0.33 and disease prevalence of $5-26 \%$, we had $80 \%$ power to detect genetic effects at an OR of 2.25 under an additive model in our samples. All the patients took $300 \mathrm{mg}$ clopidogrel and $300 \mathrm{mg}$ Aspirin before PCI, then they persistent on $75 \mathrm{mg} /$ day clopidogrel and $100 \mathrm{mg}$ Aspirin for 12 months. The inclusion criteria were: (1) Chinese Han CHD patients undergoing PCI who was born in Jin Hua (2) patients who never took clopidogrel before enrolled. The exclusion criteria were (1) patients who were allergic with Clopidogrel and Aspirin; (2) patients who experienced the bleeding and cerebrovascular disease before the last 6 months; (3) patients with severe renal and hepatic function failure; (4) patients who can live less than 12 months;(5)patients with large surgery within 1 month.

\section{DNA extraction}

We collect the blood samples in EDTA tubes and stored at $-80^{\circ} \mathrm{C}$. The extraction procession was following the manufacturer's recommendations of the whole blood genomic DNA extraction kit (Tiangen biotech company, Bei Jing, China).

\section{Platelet aggregation assays}

Blood samples for platelet function testing were done before and 7 days after PCI. Blood samples $(3 \mathrm{ml})$ were collected in the tube containing 10 [9] $\mu \mathrm{mol} / \mathrm{L}$ sodium citrate. The platelet-rich plasma (PRP) and the plateletpoor plasma (PPP) were separated by centrifuged. The PPP and PRP samples were heated to $37^{\circ} \mathrm{C}$ for $3 \mathrm{~min}$, then $20 \mu \mathrm{mol} / \mathrm{L}$ of ADP was added to the samples to measure platelet aggregation rate (PAR). (PAR beforePAR after)/ PAR before was used to calculate the platelet aggregation inhibition rate (PAIR). When PAIR is less than $10 \%$, we considered these patients as clopidogrel resistance.

\section{Genotyping assay}

Genotyping of the CYP2C19*2, CYP2C19*3 and PON1Q192R were accomplished by polymerase chain reaction (PCR). The primer sequences for PCR were as below: for CYP2C19*2, forward primer $5{ }^{`}$-ACCAGAGCTTGGCATA TTGTATCT-3`, reverse primer 5`-GATTCTTGGTGTT CTTTTACTTTCT-3`, 192 bp; for CYP2C19*3, forward primer 5 ` - TTTCATCCTGGGCTGTGCTC-3`reverse primer 5 '-TGTACTTCAGGGCTTGGTCAAT-3`, 234bp; for PON-1, forward primer $5{ }^{`}$-AAGGCTCCATCCCACATCT3 'and reverse primer 5 - CATCGGGTGAAATGTTGATT - 3`, 312 bp. PCR amplification was done by a S1000 Peltier thermal cycler (Biorad, USA) in the following conditions: Firstly, denaturing at $94{ }^{\circ} \mathrm{C}$ for $5 \mathrm{~min}$, followed by 35 cycles including at $94^{\circ} \mathrm{C}$ about $30 \mathrm{~s}$, at $60^{\circ} \mathrm{C}\left(\mathrm{CYP} 2 \mathrm{C} 19^{*} 2\right), 54^{\circ} \mathrm{C}$ (CYP2C19*3), $58^{\circ} \mathrm{C}(\mathrm{PON}-1 \mathrm{Q} 192 \mathrm{R})$ for $30 \mathrm{~s}, 72^{\circ} \mathrm{C}$ for $30 \mathrm{~s}$. Finally, extending at $72^{\circ} \mathrm{C}$ for $10 \mathrm{~min}$. All these PCR 
products were sequenced (Hangzhou Qing ke Biotechnology Co., Ltd., Hangzhou, China). According to the CYP2C19 genotype, these patients were categorized into three groups: normal metabolizers (*1/*1), intermediated metabolizers (" $1 /$ "2, $\left.{ }^{*} 1 / * 3\right)$ and poor metabolizers $\left(* 2 /{ }^{*} 2,{ }^{*} 2 / * 3, * 3 / * 3\right)$. On the basis of the PON-1Q192R genotype, these patients also could be divided into QQ(AA) genotype, QR(AG) genotype, RR(GG) genotype.

\section{Follow-up}

Patients were followed up at the 6,12 months after PCI. The incidence of recurrent angina, nonfatal MI, cerebral stroke, stent thrombosis, and sudden cardiac death were recorded as the main endpoints. The patients were consulted face to face or by telephone.

\section{Statistical analyses}

The deviation between genotype distribution and HardyWeinberg equilibrium (HWE) was analyzed by the Chisquare test. The linkage disequilibrium(LD) analysis was performed by Haploview and the haplotypes analysis was conducted by SHEsis (available on line http://analysis.biox.cn/myAnalysis.php). Mean \pm SD was used to express the continuous data, the categorical data presented as percentage. The comparisons among different groups were performed by one way analysis of variance (ANOVA). Whereas, Chi square and Fisher's exact test were suitable for the categorical variable. $p<0.05$ means there are statistically significant among different groups. Both Univariable and multivariable logistic regression analyses were used to analysis the relationship between the genotypes of PON1 Q192R, CYP2C19*2 CYP2C19 "3 and clopidogrel resistance. All these analyses were using SPSS 23.

\section{Results}

Genotype results of CYP2C19 and PON-1

CYP2C19 and PON-1 genotypes were assayed in 160 patients. The distribution of $\mathrm{CYP} 2 \mathrm{C} 19 * 2, \mathrm{CYP} 2 \mathrm{C} 19^{*} 3$, PON Q192R allelic and genotype frequency are shown in Table 1, Fig. 1. It seems no significantly difference between our results and the Hardy-Weinberg equilibrium $(p=0.553, p=0.152$ and $p=0.4$, respectively).

\section{Baseline characteristics of participants}

All the enrolled patients were divided into clopidogrel-resistant $\operatorname{group}(n=40) \quad(\operatorname{PAIR} \leq 10 \%)$ and clopidogrel-responded $\operatorname{group}(n=120) \quad(\mathrm{PAIR} \geq 10 \%)$. The baseline characteristics of these two groups were concluded in Table 2. The average age of these patients were $62.35 \pm 12.76$ years (male vs female: $75.63 \%$ vs $24.37 \%$ ). Among these patients, almost $70 \%$ of the patients presented with acute myocardial infarction (AMI). Most of the patients (91.25\%) were intervened with drug-eluting stents. The baseline of demographics, clinical presentations and drug combinations were similar between the clopidogrel responded group and the clopidogrel-resistant group $(p>0.05)$ except for the incidence of diabetes and smoking $(P<0.05)$. The genotype distribution of CYP2C19"2, "3 and PON1 Q192R among these two groups were showed in Table 3, No mutant homozygous of CYP2C19*3 genotype was found in our study. The proportion of CYP2C19*1/*1 genotype frequency was obviously higher in clopidogrel responded group $(50.83 \%$ vs $10 \%)$. While the frequency of CYP2C19 (*2/*2," $2 / * 3)$ were higher in the clopidogrel-resistant group $(27.5 \%$ vs $5,17.5 \%$ vs $0.83 \%)$. Meanwhile the proportion of patients with PON-1Q192R(GG) genotype were higher in clopidogrel resistant group than those in clopidogrel response $\operatorname{group}(67.5 \%$ vs $38.33 \%)$.

\section{CYP2C19*2,*3 and PON1 Q192R genotypes and platelet aggregation inhibition rate}

The platelet aggregation inhibition rate (PAIR) in all the CYP2C19*2, *3, PONQ192R genotypes were showed in Fig. 2. The PAIR of the patients with the genotype of CYP2C19 (*1/*2 or *2/"2) were significantly lower than those in patients with CYP2C19 $\left({ }^{*} 1 /{ }^{*} 1\right)(p=0.003, p=0.001)$. The same results were found in CYP2C19*3 genotypes. When consideration the allelic of both CYP2C19*2 and CYP2C19*3, The PAIR of intermediated metabolizers $\left(* 1 /{ }^{*} 2\right.$, " $\left.1 / * 3\right)$ and poor metabolizers $(* 2 / * 2, * 2 / * 3)$ were lower than normal metabolizers $\left(* 1 /{ }^{*} 1\right) \quad(p<0.05)$. For PON1 Q192R genotypes, the PAIR of patients with RR(GG) genotype were obviously lower than those in patients with QQ(AA) genotype $(p<0.05)$.

Table 1 Genotype distribution and allele frequency of CYP2C19*2、*3、PONQ192R

\begin{tabular}{|c|c|c|c|c|c|c|}
\hline & \multicolumn{2}{|c|}{ genotype(n/\%) } & \multicolumn{2}{|c|}{ Allele frequency(n/\%) } & \multicolumn{2}{|l|}{ HWE } \\
\hline & GG & GA & $\mathrm{AA}$ & G & A & \\
\hline $\mathrm{CYP} 2 \mathrm{C} 19^{*} 2$ & 78(48.75) & $65(40.62)$ & $17(10.63)$ & $221(69.06)$ & $99(30.94)$ & 0.533 \\
\hline $\mathrm{CYP} 2 \mathrm{C} 19^{*} 3$ & $140(87.5)$ & $20(12.5)$ & $0(0)$ & $300(93.75)$ & $20(6.25)$ & 0.152 \\
\hline PONQ192R & $73(45.62)$ & $64(40)$ & $23(14.38)$ & $210(65.62)$ & $110(34.38)$ & 0.4 \\
\hline
\end{tabular}

$p<0.05$ was considered significant. HWE Hardy-Weinberg equilibrium 

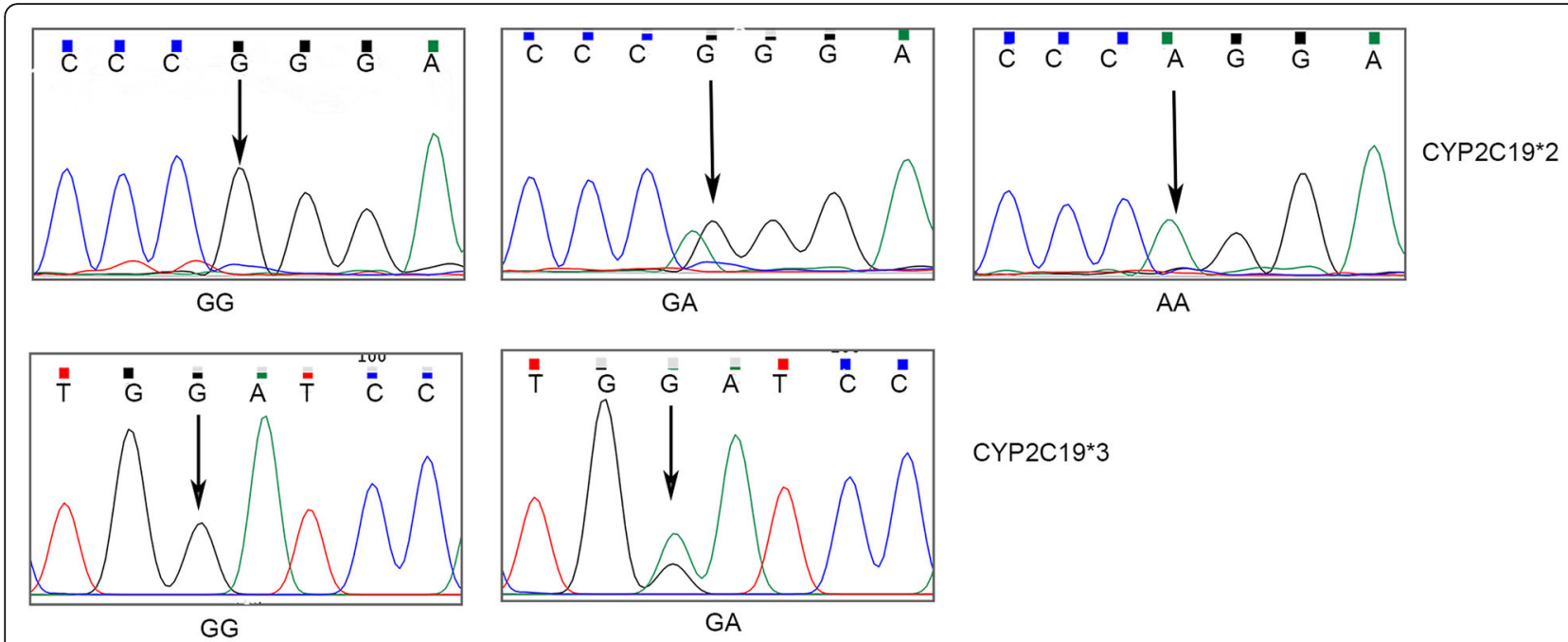

CYP2C $19 * 3$
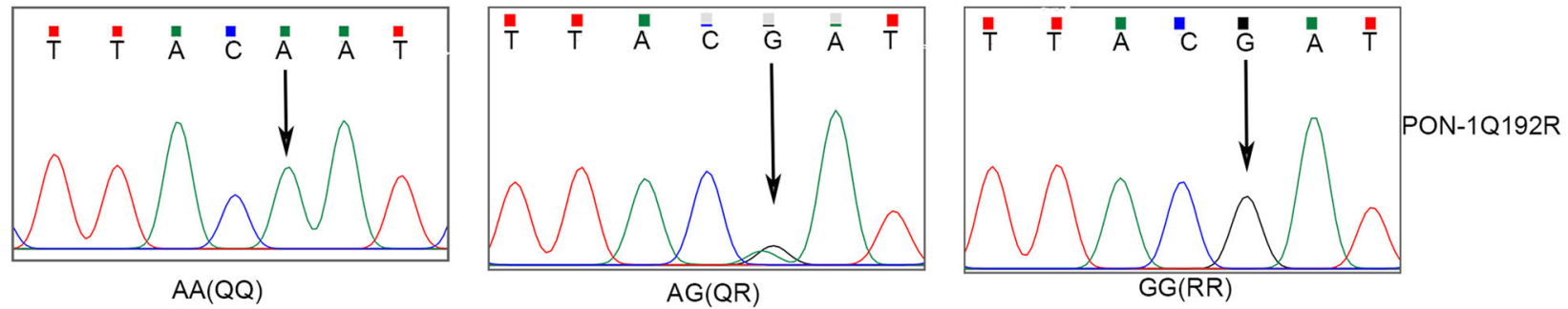

Fig. 1 Sequence of CYP2C19*2, CYP2C19*3 and PON-1Q192R. Sequence chromatogram of CYP2C19*2, CYP2C19*3 and PON-1Q192R. SNPs are indicated by arrows

\section{Relationship between CYP2C19*2, CYP2C19*3, PON1 Q192R genotype and clopidogrel responses}

Both univariate logistic regression and the multivariate logistic regression analysis were used to determine the risk factors of clopidogrel resistance. The results were shown in Table 4. The univariate logistic regression showed that CYP2C19*2 $(* 1 / * 2)$ and CYP2C19 (*2/*2) were separately 2.81 times (95\% $\mathrm{CI}, 1.12-6.59 ; p=0.03)$ and 12.47 times $(95 \% \mathrm{CI}, 3.47-41.22$; $p=0.001$ ) higher risk of clopidogrel resistance. Meanwhile, CYP2C19*3 (*1/3) predicted the risk of clopidogrel resistance (OR 5.31,95\% CI,1.96-14.41; $p<0.001$ ). Due to the combined effect of CYP2C19*2 and *3, the *2/*2 and $* 2 / 3$ genotypes showed more higher risk of clopidogrel resistances (OR 27.96, 95\%CI, 6.77-115.52; $p<0.001$; OR 106.75, 95\%CI,10.42-1093.57; $p<0.001)$.For PON1 Q192R, PON1 Q192R (RR) showed higher risk of clopidogrel resistance (OR 5.47,95\% Cl,1.19-25.23; $p=0.029$ ).

Multivariable logistic regression analysis was done after adjusting age, sex, BMI, hypertension, hyperlipidemia, type 2-DM, smoking factors. CYP2C19*2 $\left({ }^{* 1} 1 / 2\right.$, *2/"2) showed higher risk of clopidogrel resistance (OR 2.99, 95\%CI, 1.11-8.03; $p=0.03$; OR 8.62, 95\%CI, 2.2932.46; $p=0.001)$. Considered the combined effects of CYP2C19*2 and *3, CYP2C19(*1/*2, " $1 / * 3, * 2 / * 2, * 2 / * 3)$ conferred higher risk of clopidogrel resistance than
CYP2C19 $(* 1 / * 1)$.While, the PON1 Q192R genotypes (RR) was obviously associate with clopidogrel resistance(OR 5.69,95\% CI,1.06-30.47; $p=0.042)$.

\section{LD analysis and haplotype}

The LD analysis showed the LD was observed between rs4986893 and rs4244285( $r[2]=0.03)$. The $\mathrm{D}^{\prime}$ value between rs4986893 and rs4244285 was 0.995 . So the haplotype analysis for rs4986893 and rs4244285 was done by the SHEsis. The results of haplotype analysis of the two single nucleotide polymorphisms (SNPs) were showed in Table 5. The $\mathrm{AG}^{*}$ and $\mathrm{GA}^{*}$ haplotypes were associated with a significant increase in the clopidogrel resistance $(\mathrm{OR}=5.119,95 \% \mathrm{CL}=2.01-13.035, P=0.000191 ; \mathrm{OR}=$ $3.299,95 \% \mathrm{CL}=1.994-5.597, P=5.8 * \mathrm{e}-006)$.

\section{Clinical outcomes}

12 months follow-up were done in all patients. The incidence of major adverse cardiac events(MACE) during the follow-up time was $25.63 \%$.The incidence of MACE occurred less often in CYP2C19(1*/1*) patients than in CYP2C19 $\left(1^{*} / 2^{*}, 1^{*} / 3^{*}, 2^{*} / 2^{*}, 2^{*} / 3^{*}\right)$ patients (2/63vs.18/ 40, 2/63vs.3/9, 2/63vs.11/6, 2/63vs.7/1, respectively, $p<$ $0.05)$. While the incidence of MACE occurred in PON1(QQ) patients and PON1 $(\mathrm{QR}+\mathrm{RR})$ patients were 
Table 2 Baseline characteristics of study patients

\begin{tabular}{|c|c|c|c|c|}
\hline Parameters & $\begin{array}{l}\text { Total } \\
(n=160)\end{array}$ & Non-responders $(n=40)$ & $\begin{array}{l}\text { Responders } \\
(n=120)\end{array}$ & $P$ \\
\hline Age & $62.35 \pm 12.76$ & $60.83 \pm 11.47$ & $62.86 \pm 13.17$ & 0.385 \\
\hline Male/Female(n/n) & $121 / 39$ & $31 / 9$ & $90 / 30$ & 0.834 \\
\hline $\mathrm{BMI}$ & $24.03 \pm 3.06$ & $24.09 \pm 3.47$ & $24.01 \pm 2.92$ & 0.881 \\
\hline Hypertension(\%) & $108(67.5 \%)$ & $24(60 \%)$ & $84(70 \%)$ & 0.165 \\
\hline Diabetes(\%) & $40(25 \%)$ & $17(42.5 \%)$ & $23(19.17 \%)$ & $0.003^{*}$ \\
\hline smoking(\%) & $62(38.75 \%)$ & $21(52.5 \%)$ & $41(34.17 \%)$ & $0.039 *$ \\
\hline Dyslipidemia(\%) & $148(92.5 \%)$ & $36(92.31 \%)$ & 112(93.33\%) & 0.732 \\
\hline ACEI/ARB (\%) & $81(50.63 \%)$ & $19(47.5 \%)$ & $62(51.67 \%)$ & 0.716 \\
\hline $\mathrm{CCB}(\%)$ & $38(23.75 \%)$ & $9(22.5 \%)$ & $29(24.17 \%)$ & 0.508 \\
\hline Statin(\%) & $152(95 \%)$ & $36(92.31 \%)$ & 116(96.67\%) & 0.2 \\
\hline PPI (\%) & $48(30 \%)$ & 14(35\%) & $34(28.5 \%)$ & 0.272 \\
\hline Nitrates & $65(40.625 \%)$ & $18(45 \%)$ & $47(39.17 \%)$ & 0.515 \\
\hline$\beta$-receptor blocker & $148(92.5 \%)$ & $36(90 \%)$ & 112(93.33\%) & 0.488 \\
\hline Diuretics & $22(13.75 \%)$ & $6(15 \%)$ & 16(13.33\%) & 0.791 \\
\hline Rivaroxaban & $12(7.5 \%)$ & $4(10 \%)$ & $8(6.67 \%)$ & 0.488 \\
\hline Panax Notoginseng & $14(8.75 \%)$ & $5(8 \%)$ & $9(7.5 \%)$ & 0.332 \\
\hline Metal stent & $14(8.75 \%)$ & $3(7.5 \%)$ & $11(9.17 \%)$ & 0.747 \\
\hline Drug-eluting stent & $146(91.25 \%)$ & $37(92.5 \%)$ & 109(90.83\%) & 0.747 \\
\hline Infarct artery LAD & $115(71.88 \%)$ & $29(72.5 \%)$ & $86(71.67 \%)$ & 0.919 \\
\hline Infarct artery LCX & $108(67.5 \%)$ & $24(60 \%)$ & $84(70 \%)$ & 0.242 \\
\hline Infarct artery RCA & $135(84.38 \%)$ & $34(85 \%)$ & $101(84.17 \%)$ & 0.9 \\
\hline Infarct artery LM & $35(21.88 \%)$ & $8(20 \%)$ & $27(22.5 \%)$ & 0.74 \\
\hline \multicolumn{5}{|l|}{ clinical presentation } \\
\hline Angina & $25(15.63 \%)$ & $6(15 \%)$ & $19(15.83 \%)$ & 0.9 \\
\hline $\mathrm{AMI}$ & $116(72.5 \%)$ & $27(67.5 \%)$ & $89(74.16 \%)$ & 0.413 \\
\hline
\end{tabular}

CCB Calcium channel blockers

PPI Proton pump inhibitors

$A C E I / A R B$ angiotensin converting enzyme inhibitor/ angiotensin II receptor antagonist

$L A D$ left anterior descending artery

$L C X$ left circumflex artery

$R C A$ right coronary artery

$L M$ left main coronary artery

$A M I$ acute myocardial infarction

*Variable is significant difference between responders and non-responders at $p$-value $<0.05$

no significantly difference $(p<0.05)$. The results were showed in Table 6.

\section{Discussion}

Clopidogrel is a prodrug, it needs to be metabolized into an active metabolite with the activity of cytochrome P450 and paraoxonase to playing the role of antiplatelet aggregation ${ }^{(9) .}$ The variants of cytochrome P450 and paraoxonase can lead to the change of enzyme activity, especially the mutation of CYP2C19*2, CYP2C19*3, PONQ192R allelic $[17,18]$. The probe drug could be used to measure the activity of CYP450 and to point out the genotyping of CYP450 [19]. Ersin Gumus etal evaluate lansopranzole as an in vivo phenotyping probe for assessing CYP2C19 activity, they found that the poor metabolizers have lower enzyme activity [20]. Therefore, the mutation of CYP2C19*2, CYP2C19*3, PONQ192R may cause different clopidogrel response and increased rates of thrombotic events. Although several studies have reported the relationship between CYP2C19*2, CYP2C19*3 and Clopidogrel resistance. Whereas allelic variants exhibit ethnic and geographic diversity $[8,10]$. It was the first time for us to assess the relationship between CYP2C19*2, CYP2C19*3, PONQ192R allelic variants and Clopidogrel resistance and to clarify the relationship between the CYP2C19*2, CYP2C19*3, PONQ192R polymorphisms and the incidence of major adverse cardiovascular events in Jin Hua population (in the middle of Zhe Jiang province in China). The results of our study showed that the frequencies of heterozygous and 
Table 3 Distribution of CYP2C19*2, 3 and PON1 genotypes in clopidogrel responder and non-responder group

\begin{tabular}{|c|c|c|c|c|}
\hline & Genotype & $\begin{array}{l}\text { Non-responders } \\
(40)\end{array}$ & $\begin{array}{l}\text { responders } \\
(120)\end{array}$ & $P$ \\
\hline$\overline{\text { CYP2C19 }}$ & ${ }^{\mathrm{a}} 1 /{ }^{\mathrm{a}} 1(681 \mathrm{GG} / 636 \mathrm{GG})$ & $4(10 \%)$ & $61(50.83 \%)$ & $<0.001$ \\
\hline$\left({ }^{a} 2: 681 G>A\right.$ & ${ }^{\mathrm{a}} 1 /{ }^{\mathrm{a}} 2(681 \mathrm{GA} / 636 \mathrm{GG})$ & 13(32.5\%) & $45(37.5 \%)$ & 0.569 \\
\hline \multirow[t]{4}{*}{$a_{3: 636 G}>$ A) } & ${ }^{\mathrm{a}} 1 /{ }^{\mathrm{a}} 3(681 \mathrm{GG} / 681 \mathrm{GA})$ & $5(8 \%)$ & $7(5.83 \%)$ & 0.177 \\
\hline & ${ }^{\mathrm{a}} 2 /{ }^{\mathrm{a}} 2(681 \mathrm{AA} / 636 \mathrm{GG})$ & $11(27.5 \%)$ & $6(5 \%)$ & $<0.001$ \\
\hline & ${ }^{\mathrm{a}} 2 /{ }^{\mathrm{a}} 3(681 \mathrm{GA} / 636 \mathrm{GA})$ & $7(17.5 \%)$ & $1(0.83 \%)$ & $<0.001$ \\
\hline & ${ }^{\mathrm{a}} 3 /{ }^{\mathrm{a}} 3(681 \mathrm{GG} / 636 \mathrm{AA})$ & 0 & 0 & \\
\hline PONQ192R & $\mathrm{AA}(\mathrm{QQ})$ & $2(5 \%)$ & $21(17.5 \%)$ & 0.172 \\
\hline \multicolumn{5}{|l|}{$(575 \mathrm{~A}>\mathrm{G})$} \\
\hline & $A G(Q R)$ & $11(27.5 \%)$ & $53(44.17 \%)$ & 0.066 \\
\hline & GG(RR) & $27(67.5 \%)$ & 46(38.33\%) & 0.001 \\
\hline
\end{tabular}

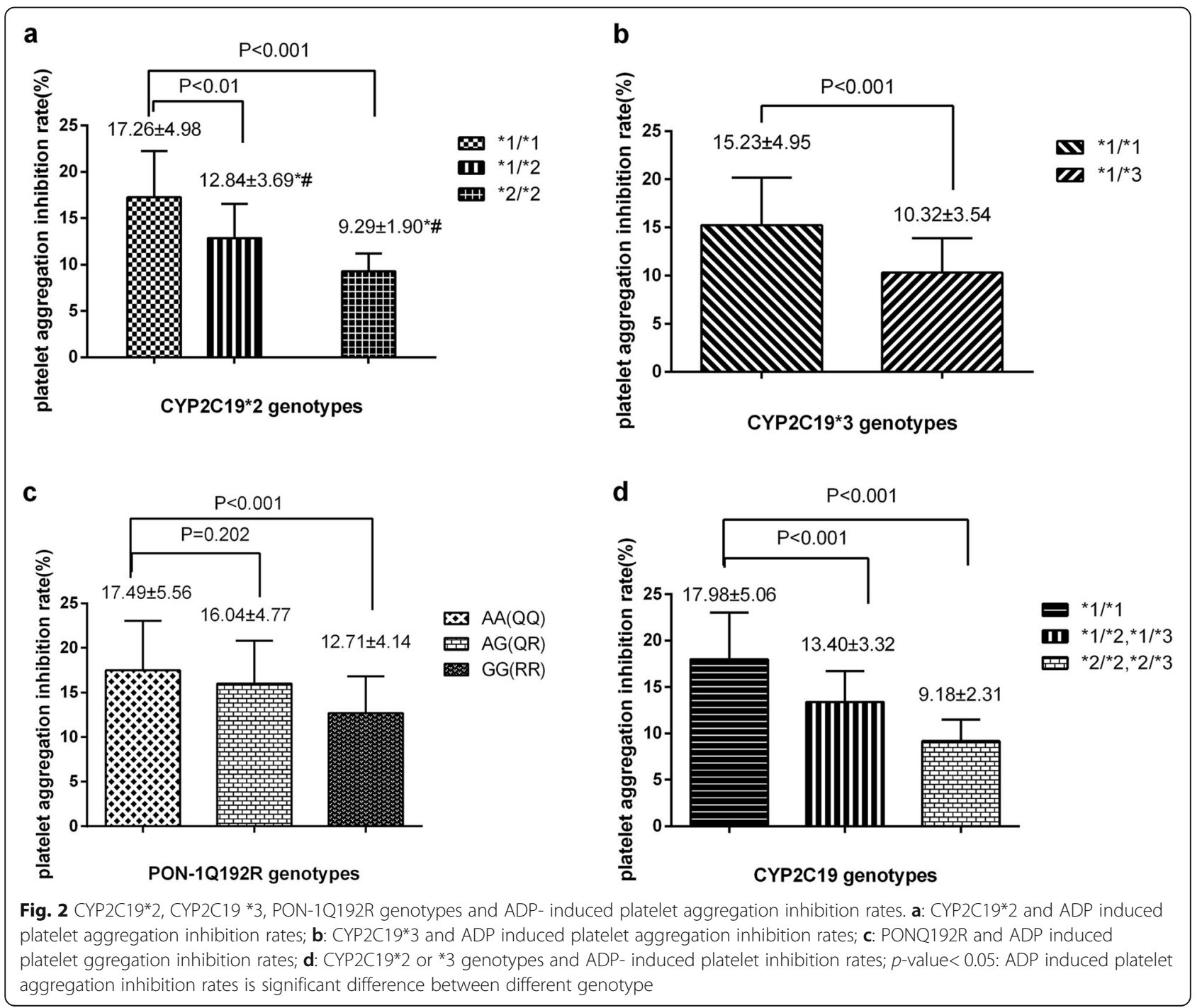


Table 4 Association between CYP2C19*2, *3, PON1 Q192R and clopidogrel resistance

\begin{tabular}{|c|c|c|c|c|}
\hline Genotype & Crude OR(95\%CL) & $P$ value & $\begin{array}{l}\text { Adjusted OR } \\
(95 \% \mathrm{CL})\end{array}$ & $P$ value \\
\hline CYP2C19*2(GG) & 1 & & 1 & \\
\hline CYP2C19*2(GA) & $2.81(1.12-6.59)$ & 0.018 & $2.99(1.11-8.03)$ & 0.03 \\
\hline CYP2C19*2(AA) & $12.47(3.77-41.22)$ & $<0.001$ & $8.62(2.29-32.46)$ & 0.001 \\
\hline CYP2C19*3(GG) & 1 & & 1 & \\
\hline CYP2C19*3(GA) & $5.31(1.96-14.41)$ & $<0.001$ & $3.64(0.98-13.56)$ & 0.054 \\
\hline $1 * / 1^{*}$ & 1 & & 1 & \\
\hline $1 * / 2^{*}$ & $4.41(1.35-14.41)$ & 0.14 & $6.65(1.77-25.04)$ & 0.005 \\
\hline $1 * / 3^{*}$ & $10.89(2.36-50.30)$ & 0.002 & $22.74(3.11-166.27)$ & 0.002 \\
\hline $2^{*} / 2^{*}$ & 27.96(6.77-115.52) & $<0.001$ & 48.49(8.16-287.97) & $<0.001$ \\
\hline $2^{*} / 3^{*}$ & $106.75(10.42-1093.57)$ & $<0.001$ & 241.32(14.59-3991.37) & $<0.001$ \\
\hline PON1(Q192R)QQ(AA) & 1 & & 1 & \\
\hline PON1(Q192R)QR(AG) & $2.68(0.56-12.90)$ & 0.22 & $3.01(0.53-17.05)$ & 0.213 \\
\hline PON1(Q192R)RR(GG) & $5.47(1.19-25.23)$ & 0.029 & $5.69(1.06-30.47)$ & 0.042 \\
\hline
\end{tabular}

$p<0.05$ : Risk is statistical significant when compared to the reference genotype

homozygous CYP2C19*2 were $40.62 \%$ and $10.63 \%$ respectively and the frequencies of heterozygous and homozygous CYP2C19*3 was $12.5,0 \%$. All genotype frequencies for both CYP2C19*2 and CYP2C19*3 alleles were consistent with Hardy-Weinberg equilibrium. The mutation of CYP2C19*2 is similarly with the results of Wei et al .[21] reported but lower than the results of Zhao et al. [22] reported. While the mutation of CYP2C19*3 showed higher than the results of Zhao et al. reported. Our study also showed that the frequencies of heterozygous and homozygous PONQ192R were 40\% and $45.62 \%$, respectively, It is consistent with the results of Xiao-Fang Tang at el [23]reported.

Our study found that both the carriers of CYP2C19*2 and CYP2C19*3 mutant allele showed attenuated response to clopidogrel therapy, after adjusted for age, sex, BMI, hypertension, hyperlipidemia, type 2-DM, smoking, we also found a synergic effect between the two alleles mutation on Clopidogrel resistance, both intermediated metabolizer $\left(* 1 /{ }^{*} 2,{ }^{*} 1 / * 3\right)$ and poor metabolizers $(" 2 / * 2, * 2 / * 3)$ all increased the Clopidogrel resistance as compare with normal metabolizers(" $\left.1 /{ }^{*} 1\right)$. Our study is consistence with The results of Studies in

Table 5 Haplotype analysis on association of CYP2C19, PON-1 gene and clopidogrel resistance

\begin{tabular}{|c|c|c|c|c|}
\hline \multirow{2}{*}{$\begin{array}{l}\text { Haplotypes } \\
\text { (rs4244285, } \\
\text { rs } \\
\text { s4986893) }\end{array}$} & \multicolumn{2}{|l|}{ Frequencies } & \multirow[t]{2}{*}{ OR $(95 \% \mathrm{CL})$} & \multirow[t]{2}{*}{$P$-values } \\
\hline & $\begin{array}{l}\text { Case group } \\
\text { N (\%) }\end{array}$ & $\begin{array}{l}\text { Control group } \\
\mathrm{N}(\%)\end{array}$ & & \\
\hline $\mathrm{AG}^{*}$ & $12(0.150)$ & $8(0.033)$ & $5.119(2.01-13.035)$ & 0.000191 \\
\hline$G A^{*}$ & $41(0.512)$ & $58(0.242)$ & $3.299(1.944-5.597)$ & $5.8 \mathrm{e}-006$ \\
\hline $\mathrm{GG}^{*}$ & $27(0.338)$ & $174(0.725)$ & $0.193(0.112-0.333)$ & $5.71 e-010$ \\
\hline
\end{tabular}

The frequency of haplotype below 0.03 was not included in the table; $P$-value $<0.05$ was defined as the level of significance
Thailand [24], Japan [25], Latin American [26], Korea [27]. While Hassani Idrissi [28] et al. showed that a synergic effect between CYP2C19*2 and CYP2C19*3 lossof-function is associated with Clopidogrel resistance but not CYP2C19*2 and CYP2C19*3 loss-of-function lonely. This may due to inter-racial differences and small sample size. We conducted the haplotype analysis for rs 4986893 and rs4244285. We found that the haplotype $\mathrm{AG}^{*}$ and $\mathrm{GA}^{*}$ were associated with an increased Clopidogrel Resistance. Our reports also indicated only homozygous PONQ192R showed attenuated response to clopidogrel therapy. This results are the same as several reports $[29,30]$. However, other studies could not discovery the influence of PON1 Q192R genotype on clopidogrel induced antiplatelet aggregation inhibition [31, 32], This may due to the small effects of PON1 Q192R polymorphism on platelet aggregation.

Many studies have proved that the CYP2C19*2 LOF alleles $\left(* 1 / * 2,{ }^{*} 2 / * 2\right)$ increase the risk of MACE [33, 34]. Our study also showed that intermediated metabolizer

Table 6 Occurrence of adverse cardiovascular events between the different CYP2C19 genotypes and PON-1 Q192R genotypes

\begin{tabular}{lllll}
\hline group & Genotype & MACE & NON-MACE & $P$ \\
\hline CYP2C19 & $* 1 / *^{*}$ & 2 & 63 & \\
& $* 1 / *^{2}$ & 18 & 40 & $<0.001$ \\
& $* 1 / *^{*}$ & 3 & 9 & 0.025 \\
& $* 2 / *^{2}$ & 11 & 6 & $<0.001$ \\
& $* 2 / *^{*}$ & 7 & 1 & $<0.001$ \\
& $\mathrm{AA}(\mathrm{QQ})$ & 3 & 20 & \\
PON-1 & $\mathrm{AG}(\mathrm{QR})$ & 13 & 51 & 0.534 \\
& $\mathrm{GG}(\mathrm{RR})$ & 25 & 48 & 0.051 \\
\hline$p<0.05$ was considered significant & & &
\end{tabular}

$p<0.05$ was considered significant 
$\left({ }^{*} 1 / * 2\right)$ and poor metabolizers $\left(* 2 /{ }^{*} 2,{ }^{*} 2 / * 3\right)$ seem to be at increased risk of adverse cardiovascular outcomes and higher rates of adverse cardiovascular events. It is similar to those studies, but Zhong et al. shed new light on no significant association between CYP2C19 polymorphisms and MACE [35]. such variation may include genetic, non-genetic, and physiologic agents among the patients. we could not find any association between MACE and PON-1 genotypes, it is in accordance with the results of Chen et al. [36] and Hulot et al. [37]. We guess that the first oxidation step for the Clopidogrel to 2-oxo-clopidogrel plays a decisive role in how much clopidogrel will enter the activation form. Therefore, the allelic mutant of CYP2C19 which play a significant role in the first oxidation step will lead to lower ADP-induced platelet aggregation inhibition rate and higher MACE. Whereas, PON-1 which is the enzyme for 2-oxoclopidogrel transforms to the active metabolite would exert a limited effect on clopidogrel activation. This might explain the small effects of PON1 Q192R polymorphism on ADP-induced platelet aggregation inhibition rate but not MACE.

There were still some limitations in our study, Firstly, the sample size was relatively small. Secondly, the follow up duration was 12 months, a longer follow up duration is needed to confirm the results. Lastly, we did not exclude the effects of other metabolism enzymes on clopidogrel resistance. Some important markers may be missing. Therefore, our study yielded the definite conclusions.

\section{Conclusion}

In summary, the polymorphism of CYP2C19 and PON-1 affect clopidogrel responsiveness. The polymorphism of CYP2C19 affect the adverse cardiovascular events but not PON-1. These findings.

Provided individual drug therapies among minority populations in JinHua in China.

\section{Abbreviations}

CHD: Coronary Heart Disease; DAPT: Dual antiplatelet therapy; MACE: Major adverse cardiac events; MPAR: Maximal platelet aggregation rate; PAIR: Platelet aggregation inhibition rate; PCl: Percutaneous Coronary Intervention; PON-1: Paraoxonase-1; PPP: Platelet-poor plasma; PRP: Plateletrich plasma
}

\section{Acknowledgments}

We thank all the study participants and study coordinators for participating in this study. We thank for JinHua Municipal Central Hospital and the Health commission of Zhejiang province.

\section{Author contributions}

ZWZ, MXC, LZ made contributions to conception, design, implement the experiment. QZ acquisition of data, analysis and interpretation of data. ZWZ preparing the original draft. ZWZ revised the manuscript critically for important intellectual content. ZWZ, MXC agreed to be accountable for all aspects of the work in ensuring the accuracy or integrity of this study. All authors read and approved the final manuscript.

\section{Funding}

This study was supported by JinHua Municipal Central Hospital and Zhejiang provincial health and family planning commission. The contact number were respectively JY2017-2-3 and 2018RC080.

\section{Availability of data and materials}

All relevant data are including in the manuscript. The datasets used and/or analyzed during the current study are available from the corresponding author upon request.

\section{Ethics approval and consent to participate}

The protocol of this study was reviewed and approved by the ethics committee of Jin Hua municipal central hospital and written informed consent was provided by all patients.

Consent for publication

Not applicable.

\section{Competing interests}

None of the authors have any potential conflicts associated with this research.

\section{Author details}

'Department of Pharmacy, Jin Hua Municipal Central Hospital, Jin Hua 32100, China. ${ }^{2}$ Department of Medical laboratory, Jin Hua Municipal Central Hospital, Jin Hua 32100, China. ${ }^{3}$ Department of Vascularcardiology, Jin Hua Municipal Central Hospital, Jin Hua 32100, China.

Received: 19 October 2019 Accepted: 20 December 2019 Published online: 03 January 2020

\section{References}

1. Switaj TL, Christensen SR, Brewer DM. Acute coronary syndrome: current treatment. Am Fam Physician. 2017;95(4):232-40.

2. Tang C, Qian H, Wang D, Qiao Y, Yan G. Prognostic value of serum Total bilirubin after percutaneous coronary intervention in patients with acute coronary syndrome. Biomed Res Int. 2019;2019:5243589.

3. Yin SH, Xu P, Wang B, Lu Y, Wu QY, Zhou ML, et al. Duration of dual antiplatelet therapy after percutaneous coronary intervention with drug-eluting stent: systematic review and network meta-analysis. BMJ. 2019;365:12222.

4. Nguyen TA, Diodati JG, Pharand C. Resistance to clopidogrel: a review of the evidence. J Am Coll Cardiol. 2005:45(8):1157-64.

5. Parodi G, Marcucci R, Valenti R, Gori AM, Migliorini A, Giusti B, et al. High residual platelet reactivity after clopidogrel loading and long-term cardiovascular events among patients with acute coronary syndromes undergoing PCI. JAMA. 2011;306(11):1215-23.

6. Bouman HJ, Schomig E, van Werkum JW, Velder J, Hackeng CM, Hirschhauser $C$, et al. Paraoxonase-1 is a major determinant of clopidogrel efficacy. Nat Med. 2011;17(1):110-6.

7. Hassani Idrissi H, Hmimech W, El Khorb N, Akoudad H, Habbal R, Nadifi S. Does i-T744C P2Y12 polymorphism modulate Clopidogrel response among Moroccan acute coronary syndromes patients? Genetics research international. 2017;2017:9532471.

8. Taubert D, von Beckerath N, Grimberg G, Lazar A, Jung N, Goeser T, et al. Impact of P-glycoprotein on clopidogrel absorption. Clin Pharmacol Ther. 2006;80(5):486-501.

9. Saiz-Rodriguez M, Belmonte C, Caniego JL, Koller D, Zubiaur P, Barcena E, et al. Influence of CYP450 enzymes, CES1, PON1, ABCB1, and P2RY12 polymorphisms on Clopidogrel response in patients subjected to a percutaneous Neurointervention. Clin Ther. 2019;41(6):1199-212 e2.

10. Hulot JS, Bura A, Villard E, Azizi M, Remones V, Goyenvalle C, et al. Cytochrome P450 2C19 loss-of-function polymorphism is a major determinant of clopidogrel responsiveness in healthy subjects. Blood. 2006;108(7):2244-7.

11. Tan SSN, Fong AYY, Mejin M, Gerunsin J, Kong KL, Chin FYY, et al. Association of CYP2C19*2 polymorphism with clopidogrel response and 1year major adverse cardiovascular events in a multiethnic population with drug-eluting stents. Pharmacogenomics. 2017;18(13):1225-39.

12. Liu Y, Liu N, Li W, Shao H, Zhi H, Li J. Relationship of CYP2C19*2 and CYP2C19*3 gene polymorphism with clopidogrel response variability and recurrent cardiovascular events in Chinese patients undergoing percutaneous coronary intervention. Pharmacology. 2013;91(3-4):165-72. 
13. Park KW, Park JJ, Kang J, Jeon KH, Kang SH, Han JK, et al. Paraoxonase 1 gene polymorphism does not affect clopidogrel response variability but is associated with clinical outcome after PCI. PLoS One. 2013;8(2):e52779.

14. Shalia KK, Shah VK, Pawar P, Divekar SS, Payannavar S. Polymorphisms of MDR1, CYP2C19 and P2Y12 genes in Indian population: effects on clopidogrel response. Indian Heart J. 2013;65(2):158-67.

15. Tselepis AD, Tsoumani ME, Kalantzi KI, Dimitriou AA, Tellis CC, Goudevenos IA. Influence of high-density lipoprotein and paraoxonase-1 on platelet reactivity in patients with acute coronary syndromes receiving clopidogrel therapy. J Thromb Haemost. 2011;9(12):2371-8.

16. Shuldiner AR, O'Connell JR, Bliden KP, Gandhi A, Ryan K, Horenstein RB, et al. Association of cytochrome P450 2C19 genotype with the antiplatelet effect and clinical efficacy of clopidogrel therapy. JAMA. 2009;302(8):849-57.

17. Su J, Li J, Yu Q, Xu X, Wang J, Yang J, et al. Association of PON1 gene promoter DNA methylation with the risk of Clopidogrel resistance in patients with coronary artery disease. J Clin Lab Anal. 2019;33(5):e22867.

18. Tan K, Lian Z, Shi Y, Wang X, Yu H, Li M, et al. The effect of CYP2C19 genotype-guided antiplatelet therapy on outcomes of selective percutaneous coronary intervention patients: an observational study. Perinat Med. 2019;16(4):301-12.

19. Tarantino G, Capone D, Contaldi P, Gianno A, Teresa M, Tufano A. Phenotyping of CYP 4501A2 activity by Total overnight salivary caffeine assessment (TOSCA) in patients on warfarin treatment: a cross-sectional study. Clin Appl Thromb Hemost. 2018;24(6):928-35.

20. Gumus E, Karaca O, Babaoglu MO, Baysoy G, Balamtekin N, Demir H, et al. Evaluation of lansoprazole as a probe for assessing cytochrome P450 2C19 activity and genotype-phenotype correlation in childhood. Eur J Clin Pharmacol. 2012;68(5):629-36.

21. Wei YQ, Wang DG, Yang H, Cao H. Cytochrome P450 CYP 2C19*2 associated with adverse 1-year cardiovascular events in patients with acute coronary syndrome. PLoS One. 2015;10(7):e0132561.

22. Zhuo ZL, Xian HP, Long Y, Liu C, Sun YY, Ma YT, et al. Association between CYP2C19 and ABCB1 polymorphisms and clopidogrel resistance in clopidogrel-treated Chinese patients. Anatol J Cardiol. 2018;19(2):123-9.

23. Tang XF, Wang J, Zhang JH, Meng XM, Xu B, Qiao SB, et al. Effect of the CYP2C19 2 and 3 genotypes, ABCB1 C3435T and PON1 Q192R alleles on the pharmacodynamics and adverse clinical events of clopidogrel in Chinese people after percutaneous coronary intervention. Eur J Clin Pharmacol. 2013;69(5):1103-12.

24. Tresukosol D, Suktitipat B, Hunnangkul S, Kamkaew R, Poldee S, Tassaneetrithep B, et al. Effects of cytochrome P450 2C19 and paraoxonase 1 polymorphisms on antiplatelet response to clopidogrel therapy in patients with coronary artery disease. PLoS One. 2014;9(10):e110188.

25. Jinnai T, Horiuchi H, Makiyama T, Tazaki J, Tada T, Akao M, et al. Impact of CYP2C19 polymorphisms on the antiplatelet effect of clopidogrel in an actual clinical setting in Japan. Circ J. 2009;73(8):1498-503.

26. Rodrigues-Soares F, Penas-Lledo EM, Tarazona-Santos E, Sosa-Macias M, Teran E, Lopez-Lopez M, et al. Genomic ancestry, CYP2D6, CYP2C9 and CYP2C19 among Latin-Americans. Clin Pharmacol Ther. 2019.

27. Lee JM, Park S, Shin DJ, Choi D, Shim CY, Ko YG, et al. Relation of genetic polymorphisms in the cytochrome P450 gene with clopidogrel resistance after drug-eluting stent implantation in Koreans. Am J Cardiol. 2009;104(1):46-51.

28. Hassani Idrissi H, Hmimech W, Khorb NE, Akoudad H, Habbal R, Nadifi S. A synergic effect between CYP2C19*2, CYP2C19*3 loss-of-function and CYP2C19*17 gain-of-function alleles is associated with Clopidogrel resistance among Moroccan acute coronary syndromes patients. BMC Res Notes. 2018;11(1):46.

29. Li X, Wang Z, Wang Q, Xu Q, Lv Q. Clopidogrel-associated genetic variants on inhibition of platelet activity and clinical outcome for acute coronary syndrome patients. Basic Clin Pharmacol Toxicol. 2019;124(1):84-93.

30. Marchini JF, Pinto MR, Novaes GC, Badran AV, Pavao RB, Figueiredo GL, et al. Decreased platelet responsiveness to clopidogrel correlates with CYP2C19 and PON1 polymorphisms in atherosclerotic patients. Braz J Med Biol Res. 2017;50(1):e5660.

31. Fontana P, James R, Barazer I, Berdague P, Schved JF, Rebsamen M, et al. Relationship between paraoxonase-1 activity, its Q192R genetic variant and clopidogrel responsiveness in the ADRIE study. J Thromb Haemost. 2011; 9(8):1664-6.

32. Sibbing D, Koch W, Massberg S, Byrne RA, Mehilli J, Schulz S, et al. No association of paraoxonase-1 Q192R genotypes with platelet response to clopidogrel and risk of stent thrombosis after coronary stenting. Eur Heart J. 2011;32(13):1605-13.
33. Oh IY, Park KW, Kang SH, Park JJ, Na SH, Kang HJ, et al. Association of cytochrome P450 2C19*2 polymorphism with clopidogrel response variability and cardiovascular events in Koreans treated with drug-eluting stents. Heart. 2012;98(2):139-44.

34. Trenk D, Hochholzer W, Fromm MF, Chialda LE, Pahl A, Valina CM, et al. Cytochrome P450 2C19 681G>a polymorphism and high on-clopidogrel platelet reactivity associated with adverse 1-year clinical outcome of elective percutaneous coronary intervention with drug-eluting or baremetal stents. J Am Coll Cardiol. 2008;51(20):1925-34.

35. Zhong Z, Hou J, Zhang Q, Li B, Li C, Liu Z, et al. Effect of cytochrome P450 2C19 polymorphism on adverse cardiovascular events after drug-eluting stent implantation in a large Hakka population with acute coronary syndrome receiving clopidogrel in southern China. Eur J Clin Pharmacol. 2018;74(4):423-31.

36. Chen DY, Wang CY, Wen MS, Lee TH, Chu Y, Hsieh MJ, et al. Paraoxonase-1 is not a major determinant of stent thrombosis in a Taiwanese population. PLoS One. 2012;7(6):e39178.

37. Hulot JS, Collet JP, Cayla G, Silvain J, Allanic F, Bellemain-Appaix A, et al. CYP2C19 but not PON1 genetic variants influence clopidogrel pharmacokinetics, pharmacodynamics, and clinical efficacy in postmyocardial infarction patients. Circ Cardiovasc Interv. 2011;4(5):422-8.

\section{Publisher's Note}

Springer Nature remains neutral with regard to jurisdictional claims in published maps and institutional affiliations.
Ready to submit your research? Choose BMC and benefit from:

- fast, convenient online submission

- thorough peer review by experienced researchers in your field

- rapid publication on acceptance

- support for research data, including large and complex data types

- gold Open Access which fosters wider collaboration and increased citations

- maximum visibility for your research: over $100 \mathrm{M}$ website views per year

At BMC, research is always in progress.

Learn more biomedcentral.com/submissions 